ISSN: 2162-3104 Print/ ISSN: 2166-3750 Online

Volume 8, Issue 3 (2018), pp. 1316-1327

(C) Journal of International Students

http://jistudents.org/

doi: 10.5281/zenodo. 1254586

\title{
Peers to Peers: Developing a Student-Coordinated Conversation Partner Program
}

\author{
Ron Aaron \\ Baruch College, USA \\ Carmen Cedeño \\ Baruch College, USA \\ Elisabeth Gareis \\ Baruch College, USA \\ Lalit Kumar \\ Baruch College, USA \\ Abhinaya Swaminathan \\ Baruch College, USA
}

\section{ABSTRACT}

The lack of meaningful interaction between domestic and international students is a persistent concern in international higher education. Conversation partner programs are a promising measure to promote the rich and repeated contact necessary for the development of intercultural relationships and communication skills. This article describes the process of launching and managing a successful student-coordinated conversation partner program with no or minimal funding. The five core team members (two faculty advisors and three student leaders) explain why they created or joined the program, their responsibilities, what worked, what was challenging, and what they recommend should other institutions want to start a similar program.

Keywords: collaboration, communication, conversation partner program, culture, friendship, student-coordinated 
In September 1945, Senator J. William Fulbright introduced a bill in the U.S. Congress to fund the "promotion of international good will through the exchange of students" (U.S. Department of State, n.d.), which was based upon the principles of international partnership and mutual understanding. International student exchange remains one of the primary ways for U.S. universities to internationalize. Unfortunately, studies show that international students often interact more with conationals or other international students than with domestic students (e.g., Rose-Redwood \& Rose-Redwood, 2013), and a third or more of international students in the United States and other popular destination countries have no meaningful relationships with host nationals (e.g., Gareis, 2012). This situation is causing concerns that genuine internationalization is not achieved and that neither sojourners nor hosts derive maximum benefits.

Ward, Masgoret, and Gezentsvey (2009) call for institutions to increase qualitatively rich and repeated contact in order to facilitate crosscultural interactions between international and domestic students. Towards this end, universities' strategic development plans should include specific classroom practices and programs designed to foster such contact. An example with particular potential is conversation partner programs as they not only provide rich and repeated contact but also focus on key factors impeding relationship development: fostering oral communication skills, fluency, and social relaxation when conversing across cultural barriers (Gareis, Merkin, \& Goldman, 2011).

Conversation partner programs require resources in the form of staffing and management that may not be available in some institutions. What follows is the description of a student-coordinated program launched without any initial funding.

\section{PROGRAM DESIGN}

In fall 2012, the two faculty authors, Ron Aaron and Elisabeth Gareis, met to launch a conversation partner program (CPP) at Baruch College. The college has a sizable number of students (immigrants as well as international students) who don't speak English as a native language. We decided to match native and nonnative speakers, with the goal of fostering nonnative speakers' comfort in conversing in English, native speakers' ease in communicating across language barriers, and both native and nonnative speakers' expansion of cultural knowledge and development of intercultural relationships. After attending an orientation, student pairs were to meet at least six times during the semester for approximately an hour. In addition, events (such as game night) were to be offered for CPP participants to 
socialize. In line with established conditions for optimal intergroup contact (Allport, 1954), the program was structured so that native and nonnative speakers have equal status (i.e., the program was not to be seen as a tutorial service but as a peer collaboration, with the goal of both native and nonnative speakers benefitting equally).

The unique aspect of the program is that it was launched with minimal funding and operated by student volunteers. Three undergraduate students (the student authors of this article) were recruited as lead coordinators. Two of these students were international students from Italy and India, and the third was a local student with roots in the Dominican Republic. In addition, each student leader headed a committee of 5-6 student coordinators and oversaw one of the program's three areas of operation: administration, events, and communication and technology.

During the pilot semester in 2013, 42 students participated. Feedback was excellent, and the program quickly grew to a current average of over 300 participants per semester. Roughly representative of the college's overall student population, the vast majority of participants are undergraduate students with business-related majors. Likewise, the racial and ethnic composition of the native speaker participants parallel that of the student body, which is $40 \%$ Asian, $31 \%$ Caucasian, $17 \%$ Hispanic, and $11 \%$ African American. As to the international students, currently the top five native languages of CPP participants are Chinese, Korean, French, Japanese, and Turkish, which largely coincides with the languages spoken in the top home countries of international students at the college overall. Although the gender ratio at the college is roughly half female and half male, females outnumber males in the CPP 2:1.

\section{PERSONAL NARRATIVES}

What follows are the personal narratives of the five core team members. They each reflect on their rationale for creating or joining the program, their responsibilities, their perception of what worked and what was challenging, and their recommendations for others looking to launch similar programs.

\section{Ron Aaron: Co-Founder and Faculty Advisor}

\section{Why I Helped Create the Program}

Working in the Office of the Vice President for Student Affairs, I met with students on a broad array of issues. I found that nonnative speakers were often rather quiet throughout our meetings. They were not comfortable sharing their thoughts, and, if they did, they tended to be very brief and softspoken. I wondered, if they acted this way when I engaged them, what 
might be happening in their classes. Did they speak up and ask questions, and did they feel comfortable in approaching their professors in office hours? I felt that we had to find a way to make these students gain confidence and comfort in conversing, and I consulted with my colleague, Elisabeth Gareis. This became the seed for the establishment of our peer-run CPP.

\section{My Responsibilities}

I was responsible for securing funding support, arranging rooms for events, developing a recruitment strategy for participants, and structuring the motivational and leadership experiences for the volunteer student leaders and their teams of coordinators.

\section{What Worked}

Students who met on a regular basis with their partner generally were very satisfied. Nonnative speakers noted a greater degree of comfort to converse, native speakers developed a cross-cultural sensitivity as they learned a great deal about their partner, and both often mentioned a sense of friendship. Clearly nonnative speakers who maximized their involvement in the program also developed a much greater comfort in their ability to ask questions and to develop confidence in approaching other students and faculty members in the future.

\section{What Was Challenging}

About a quarter of the students who had applied to the program never really participated beyond attending an orientation session or one or two meetings with their matched partner. Even though all students were told to contact the administrative team should their partner be unresponsive, a lot of the students just did not do so. As a result, we added a note to the application form, saying that students should only apply if they can commit to meeting their partner six or more times. Another challenge was that the attendance at events was not as great as we had hoped. Other than taking part in our mandatory orientation session, participants were not required to attend any of the social and fun programs that were meant to further enhance their opportunity to converse and share with other attendees some of their thoughts and perspectives. One reason may be that the event meeting times conflicted with their class or work schedules.

\section{My Recommendations}

A successful student-coordinated program needs continuity in quality student leadership and coordinators, who are good communicators. In addition, feedback from the participants is important, ideally including 
face-to-face interaction between student participants and the student coordinators or faculty advisors. It is essential to get to know as many "players" as possible to motivate them personally, secure meaningful feedback, and identify talent that could possibly take on broader responsibility in the following year. Finally, financial support for the development of promotional materials and the purchase of light refreshments for events is a necessity. To solve this problem, we registered the CPP as a student club, but the funding was only rudimentary. Developing an advisory board that includes some key college administrators might be the best way to secure some of the needed funding.

\section{Elisabeth Gareis: Co-Founder and Faculty Advisor}

\section{Why I Helped Create the Program}

As a professor in intercultural communication with a research focus on intercultural friendship, I have long been concerned with the relative lack of friendship between international and domestic students as well as the scarcity of research on measures for fostering interaction and friendship development. The idea of a student-coordinated CPP interested me because (1) it created a platform for the rich and repeated contact that promotes relationship formation; (2) it focused on conversation, which is often not part of the English-language training of international students abroad but essential for relationship initiation and maintenance; and (3) it allowed international and domestic students to collaborate in the management of the program and therefore fulfilled Allport's (1954) conditions for optimal intergroup contact (i.e., equal status, common goals, cooperation, and support of the authorities). Last but not least, I was excited about the benefits for the domestic participants, who rarely study overseas and would gain a greater global perspective through close contact with their international partners.

\section{My Responsibilities}

I prepared the online application and assessment instruments (e.g., an initial "check-in" and a final feedback survey), kept enrollment and satisfaction statistics, created a handbook (with FAQs, suggested conversation topics, and tips for conversation management), and an online orientation for students unable to attend the face-to-face orientation.

\section{What Worked}

Creating an effective program from the bottom up gave all student coordinators as well as the faculty advisors a wonderful sense of accomplishment. Enrollment has been sustained at over 300 students per 
semester for more than five years now, which is fantastic. Most important, satisfaction levels are high, with students reporting gains in cultural knowledge and communication competence, and the development of friendships with their partners.

\section{What Was Challenging}

By far the most challenging aspect was project management. Many tasks were dependent on meticulous coordination of time and people (e.g., scheduling rooms, ordering refreshments, making sure that rooms were equipped with writing utensils, etc.). Although I created a detailed timeline, it was difficult to ensure that team leaders and their coordinating teams adhered to it. In addition, when students graduate, the student leadership changes, requiring renewed training from the ground up. Also, launching the program was time-consuming. In the initial years, I spent a significant amount of time on creating the materials (forms, surveys, handbook, etc.) and building the CPP. Still, the success of the program made it all worthwhile.

\section{My Recommendations}

On a practical level, I recommend that faculty and students looking to create a similar program employ project-management software to define tasks clearly and monitor their completion. On a broader level, a recurring comment on feedback surveys was that the CPP takes students "out of their comfort zone" and allows them to "meet someone whom they would not have met otherwise." This clearly shows that institutions should not expect for connections to happen simply because international and domestic students share space; instead, they should create an infrastructure that actively promotes contact and assists students in forging connections. I recommend that faculty members have the courage to initiate the creation of a program. Although it requires commitment and energy, working in a team with students is an immensely rewarding experience; plus, it gives student coordinators tangible skills for the workplace and an introduction to civic engagement that can change their lives.

\section{Lalit Kumar: Leader of Administrative Team}

\section{Why I Joined}

What attracted me to the CPP was the opportunity to give back and to create an atmosphere of shared community among native and nonnative speakers. As a high school exchange student from Italy, I was fortunate to get honest feedback about my English from my American host family. This 
was critical in providing me with a solid foundation for communicating and navigating American culture with an increased level of confidence.

\section{My Responsibilities}

My team's primary responsibilities were managing the application process (e.g., distributing the application forms and matching partners) and to maintain ongoing communication with the program participants (e.g., in case there were questions or conflicts, such as partners dropping out due to unforeseen circumstances). Our highest objective was addressing student concerns throughout the semester in a consistent and timely manner.

\section{What Worked}

There are strong benefits in having a program managed by student volunteers as opposed to college staff. Native speakers are genuinely inclined to devote their full attention to their partners and do not view this as a job or obligation. Similarly, nonnative speakers typically find it more beneficial (and comfortable) to interact with students in their own age group as opposed to college staff. We had a high level of satisfaction that led numerous participants to return as volunteers the following year, and to get some of their friends to join as well.

\section{What Was Challenging}

It was quite easy to attract nonnative speakers to the CPP, but challenging to attract enough native speakers. We had to find ways to emphasize to native speakers the benefits of participating in the CPP and to encourage them to commit to helping another student over the course of an entire semester.

\section{My Recommendations}

Recruiting student leaders that are truly passionate about breaking down barriers between native and nonnative speakers is key for other institutions considering the establishment of a CPP. I have come to realize that ambitious goals cannot be reached without surrounding yourself with other ambitious individuals.

\section{Abhinaya Swaminathan: Leader of Events Team}

\section{Why I Joined}

As an international student from India, I was especially conscious of the behavioral patterns of international students, who have a tendency to congregate with others of similar background. One reason for this is the lack of structures on college campuses to kindle cross-cultural interactions, and I 
saw the CPP as a means for students to experience such interactions. I was also attracted to the CPP because it was brand-new and provided me with an opportunity to co-shape its peers-serving-peers structure in productive and enriching ways. I not only learned about group dynamics as a result of working with a leadership team, I also became more prepared to face situations where cross-cultural interactions are likely to occur. This is an invaluable skill in today's global workplace and social environments.

\section{My Responsibilities}

I was in charge of the events team, which created, planned, and hosted the orientations and an array of interactive events.

\section{What Worked}

I felt that peers leading peers enhanced our ability to achieve buy-in from the student body. Utilizing international students as coordinators strengthened our ability to design an effective program.

\section{What Was Challenging}

Although we had some really creative events (e.g., ice skating, mini golf, game night), attendance was not optimal. The issue was likely the large group size (over $300 \mathrm{CPP}$ student participants), which made the marketing of events via mass e-mail somewhat impersonal. Also, students joined as coordinators because of their general interest in the CPP's mission, and it was challenging to define their specific roles within each committee.

\section{My Recommendations}

Most importantly, the leadership needs to believe that engaging with diversity is important on a college campus, be committed to the mission of the program, and seek student buy-in at all levels. It is also essential to obtain feedback, which requires repeated check-ins with the participants. Finally, roles and expectations within the student leadership should be clearly defined and committee members recruited with specific job descriptions in mind.

\section{Carmen Cedeno: Leader of Communication and Technology Team}

\section{Why I Joined}

I love communicating with people and learning about different cultures by knocking down communication barriers. Additionally, I thoroughly enjoy helping others who struggle with English, since my mother is Dominican and does not speak English well. I saw the CPP as the perfect opportunity to learn more about the people that make up the diverse 
community at our college, while helping others navigate college life. I strongly feel that I am now able to understand nonverbal and verbal cues that differ across cultures in a more conscious way. Additionally, I feel that the program strengthened my empathy and also helped develop my leadership skills for the workplace.

\section{My Responsibilities}

My team was responsible for social media marketing and the design of digital marketing material, such as e-mail campaigns, digital flyers, and event sign-ups as well as website maintenance.

\section{What Worked}

The program benefited from being run by student volunteers in that the student volunteers shared a common goal and passion for the program. There is more of an authentic flavor and altruistic mission when it is being managed by student volunteers.

\section{What Was Challenging}

Most of our initiatives were very successful in attaining organic growth for the program; however, it was difficult to manage expectations and projects when only a few members of the team had the necessary skill sets (e.g., graphic design, social media marketing, event management, and budgeting). It was also hard to attract native speakers who truly felt a passion for the program and wanted to serve as coordinators. While nonnative speakers were willing to help, the program needed strong native speakers able to navigate the political landscape.

\section{My Recommendations}

If someone were to create a CPP elsewhere, I would recommend to find a faculty mentor who understands intercultural communication. The student volunteers should have a passion for communication and helping others, and to do this from a truly altruistic point of view. It is incredibly rewarding to be able to directly impact the life of one student without money or college credits affecting someone's motivation.

\section{UPDATE AND CONCLUDING REFLECTIONS}

Since its inception, assessments and feedback have led to the revision of some design elements of the CPP:

- Initially, more nonnative than native speakers applied to participate. We employed a multi-pronged approach to address the issue. We 
increased institutional support by promoting the CPP as a way to expand the global perspective of domestic students and secured the assistance of the associate provost, whose announcements of the CPP to all faculty now include the call for more native speakers. We also intensified recruitment of native speakers through mainstream student leadership organizations as a means to enhance personal growth and by targeting departments with a focus on communication across cultural and linguistic lines (e.g., Communication Studies and Modern Languages). Finally, we asked native speakers if they were willing to have two partners, with whom they would meet separately. Consistently, more than $50 \%$ of native speakers have been willing to do so. In combination, these efforts have been exceedingly successful. We have no nonnative speakers on waiting lists.

- In order to increase semester-long commitment, we created a certificate for students, who met their partner seven or more times and an "ambassadorship" for students who, additionally, attended at least four events.

- A faculty member in Computer and Information Systems volunteered his time to design a computerized partner-matching program that helped the CPP move from a time-consuming and complicated manual matching process to a largely automatic one. The matching criteria are native language, gender preference, and time availability. With many students commuting and working outside of school, matching for availability is the most difficult task, precluding the inclusion of additional criteria (e.g., hobbies and interests). Two manual steps remain, however: Prior to the automatic matching, the administrative committee sorts through special requests (e.g., cultural preferences) and tries to accommodate them. In addition, students are matched manually if someone's partner drops out during the semester.

- We decided to pay the three core student leaders a small stipend, funded through an endowment for internationalization efforts at the college. The ability to attract students to leadership positions has not been affected by the stipends, however. The program worked just as well without the stipends.

- When one of the two faculty founders retired and the other went on sabbatical, we decided to hire a faculty director of the program. The faculty director receives one course's worth of release time per 
semester, paid for by Student Affairs. Faculty mentorship has proven essential to the CPP in order to ensure continuity, nurture leadership and communication skills, and provide oversight. However, all day-to-day operations and much of the planning is handled exclusively by the student leaders and their teams. The low cost and excitement engendered by being peer-focused sets the program apart and makes it a viable model for a variety of other institutions.

The CPP is now an established resource and one of the places at the college where students can further their communication skills, expand their global perspectives, and be part of a truly diverse community. End-ofsemester assessments attest to positive change in communication skills, cultural knowledge, and relationship development. We have not assessed long-term effects (e.g., friendship duration and alumni networking), but we plan to do so in the near future.

Conversation partner programs are catalysts for the kind of interaction between domestic and international students that is at the basis for long-term friendship formation and networking. With internationalization often focused on curricular development, partner programs also fill an important gap by allowing students not only to apply knowledge gained in their academic work but also to learn directly from the cultural diversity of other students for the personal growth and mutual benefit of every participant. We believe that institutions should make engagement with cultural diversity an integral part of students' educational experience and reinforce in students the value of making a difference in the lives of others. Peer-coordinated conversation partner programs provide this intercultural and civic engagement. They are an ideal model for what community involvement can be within our collegiate environments.

\section{REFERENCES}

Allport, G. (1954). The nature of prejudice. New York: Addison-Wesley.

Gareis, E. (2012). Intercultural friendship: Effects of home region and sojourn location. Journal of International and Intercultural Communication, 5(4), 309-328.

Gareis, E., Merkin, R., \& Goldman, J. (2011). Intercultural friendship: Linking communication variables and friendship success. Journal of Intercultural Communication Research, 40(2), 155-173.

Rose-Redwood, C., \& Rose-Redwood, R. (2013). Self-segregation or global mixing? Social interactions and the international student experience. Journal of College Student Development, 54(4) 413-429.

U.S. Department of State. (n.d.). Fulbright program history. Retrieved from http://eca.state.gov/fulbright/about-fulbright/history 
Ward, C., Masgoret, A.M., \& Gezentsvey, M. (2009). Investigating attitudes toward international students: Program and policy implications for social integration and international education. Social Issues and Policy Review, 3(1), 79-102.

RON AARON, EdD, is Professor Emeritus in the Department of Student Development and Counseling at Baruch College, CUNY. His research focused on the impact of student engagement in the out-of-classroom growth of college students. Email: ronald.aaron@baruch.cuny.edu

CARMEN CEDEÑO earned her BA in Corporate Communication from Baruch College, CUNY. She is now marketing manager at TravelBound in New York City. Email: ccedeno.21@gmail.com

ELISABETH GAREIS, EdD, is a Professor in the Department of Communication Studies, Baruch College/CUNY. Her major research interests lie in the area of intercultural friendship and oral proficiency for nonnative speakers. Email: egareis@baruch.cuny.edu

LALIT KUMAR earned his BBA in Finance from Baruch College, CUNY. He currently serves as a Credit Risk Associate at Morgan Stanley in their office in Budapest, Hungary.

ABHINAYA SWAMINATHAN earned her BA in Economics as well as Political Philosophy and Political Economy (double major) from Baruch College, CUNY. She is completing her final year of study for her JD degree at Harvard Law School. 